\title{
Leptin inhibits proliferation of breast cancer cells at supraphysiological concentrations by inhibiting mitogen-activated protein kinase signaling
}

\author{
MICHAEL WEICHHAUS ${ }^{1}$, JOHN BROOM ${ }^{1}$, KLAUS WAHLE ${ }^{2}$ and GIOVANNA BERMANO ${ }^{1}$ \\ ${ }^{1}$ Centre for Obesity Research and Epidemiology (CORE), Institute for Health and Welfare Research, \\ Robert Gordon University, Aberdeen AB10 7GJ; ${ }^{2}$ Cancer Medicine Research Group, \\ School of Medicine and Dentistry, University of Aberdeen, Medical School, Aberdeen AB25 2ZD, UK
}

Received August 23, 2013; Accepted February 18, 2014

DOI: $10.3892 / \mathrm{ol} .2014 .2085$

\begin{abstract}
Leptin is a hormone secreted by white fat tissue and signals the amount of overall body fat to the hypothalamus. The circulating concentration of leptin correlates with the level of obesity. Breast cancer risk is higher in obese postmenopausal women compared with postmenopausal women of a normal weight, and high leptin concentrations may contribute to this risk. In the present study, SK-BR-3 and MDA-MB-231 breast cancer cell lines were treated with various concentrations $(6.25-1,600 \mathrm{ng} / \mathrm{ml})$ of recombinant leptin and changes in cell proliferation were assessed. The SK-BR-3 breast cancer cells exhibited a concentration-dependent increase in proliferation with physiological leptin concentrations $(<100 \mathrm{ng} / \mathrm{ml})$, but no further increase in proliferation at high leptin concentrations $(>100 \mathrm{ng} / \mathrm{ml}$ ) was observed. Cell proliferation was not affected at supraphysiological leptin concentrations $(>800 \mathrm{ng} / \mathrm{ml})$ in SK-BR-3 cells, whereas it decreased in MDA-MB-231 cells. Therefore, cell signaling and cell cycle changes were assessed at supraphysiological concentrations $(1,600 \mathrm{ng} / \mathrm{ml})$. In the two cell lines, leptin treatment decreased the mitogen-activated protein kinase (MAPK) cell signaling pathway activation. Leptin treatment did not increase Akt phosphorylation or significantly alter the cell population distribution across cell cycle stages. To the best of our knowledge, leptin-induced growth inhibition of breast cancer cells at supraphysiological concentrations has not been reported in the literature to date, and the findings of this study suggest that reduced MAPK activity may be the underlying cause. Thus, the effect of leptin on breast cancer growth warrants further investigation since
\end{abstract}

Correspondence to: Dr Giovanna Bermano, Centre for Obesity Research and Epidemiology (CORE), Institute for Health and Welfare Research, Robert Gordon University, Riverside East, Garthdee Road, Aberdeen AB10 7GJ, UK

E-mail: g.bermano@rgu.ac.uk

Key words: leptin, breast cancer, obesity, cell proliferation, mitogen-activated protein kinase cell signaling pathway leptin is considered to be one of the main mediators in the obesity-breast cancer connection.

\section{Introduction}

Obesity, the accumulation of excess fat tissue, is a risk factor for the development of postmenopausal breast cancer (1). The molecular changes in metabolism associated with obesity are thought to contribute to this phenomenon (2). One of these molecular changes is increased circulating leptin levels in obese individuals (3). Leptin is a $16 \mathrm{kDa}$ peptide hormone predominantly produced by white fat tissue (4). Its main function is to signal to the hypothalamus, which in response regulates satiety and energy expenditure (5). Notably, leptin is also responsible for the normal formation of the mammary gland in humans (6), suggesting an involvement in mammary tissue growth and differentiation, and potentially malignant transformation. Epidemiologically, leptin concentrations are higher in patients with breast cancer compared with healthy individuals, independent of body weight (7). Additionally, leptin receptor (Ob-R) expression is increased in breast tumor tissue compared with surrounding tissue (8). Breast cancer cell lines have also been found to express leptin and Ob-R (9).

Previous in vitro experiments investigating the effects of leptin treatment on cell proliferation and tumor growth have revealed conflicting results. In MDA-MB-231 breast cancer cells, leptin induced a robust concentration-dependent increase in proliferation in two independent studies $(10,11)$. Conversely, in MCF-7 breast cancer cells, leptin treatment increased (12) and decreased (11) proliferation. Similarly, in human epidermal growth factor (HER)-2 overexpressing SK-BR-3 breast cancer cells, leptin treatment increased proliferation between 5 and $50 \mathrm{ng} / \mathrm{ml}$, but not at $100 \mathrm{ng} / \mathrm{ml}$ (11). These controversial findings warrant the need for further investigation into the effects of leptin on proliferation in a human breast cancer in vitro cell system.

Notably, a number of studies investigating the effect of cytokines on proliferation changes in cell culture models used concentrations which are several-fold greater than the highest known physiological concentration, such as insulin treatment $(13,14)$ or tumor necrosis factor- $\alpha$ treatment $(15,16)$. 
However, previous studies investigating the effect of leptin treatment on proliferation in breast cancer cells $(10,11,17) \mathrm{did}$ not or only marginally exceeded maximal physiological leptin concentrations of $100 \mathrm{ng} / \mathrm{ml}$ (3). The highest leptin concentration used in vitro to examine changes in T47D breast cancer cell proliferation was $1,000 \mathrm{ng} / \mathrm{ml}$. However, increased cell proliferation was only observed with up to $100 \mathrm{ng} / \mathrm{ml}$ leptin (18). Thus, while previous data appear to indicate a growth inhibitory effect of leptin at above physiological concentrations, it has not yet been fully investigated. Therefore, the present study aimed to explore the effects of supraphysiological leptin concentrations on proliferation in two breast cancer cell lines.

The present study aimed to investigate the effects of physiological and supraphysiological levels of leptin $(\leq 1,600 \mathrm{ng} / \mathrm{ml})$ on proliferation in SK-BR-3 and MDA-MB-231 breast cancer cells, two cell lines representative of HER-2-positive and basal-type breast cancer subtypes, respectively. The activation of phosphatidylinositide 3-kinase (PI3K) and mitogen-activated protein kinase (MAPK) cell signaling pathways and distribution across cell cycle stages were assessed in the two cell lines following treatment with $1,600 \mathrm{ng} / \mathrm{ml}$ leptin.

\section{Materials and methods}

Cell lines. SK-BR-3 and MDA-MB-231 breast cancer cell lines were purchased from the American Type Culture Collection (Manassas, VA, USA). The two cell lines were routinely cultured in RPMI-1640 medium (including 25 mM HEPES, 1X Glutamax ${ }^{\mathrm{TM}}$; Gibco, Paisley, UK) supplemented with $10 \%$ fetal calf serum (FCS; Pierce Biosciences, Cramlington, UK), $100 \mathrm{U} / \mathrm{ml}$ penicillin and $100 \mu \mathrm{g} / \mathrm{ml}$ streptomycin (Gibco).

Bromodeoxyuridine (BrdU) proliferation assay. Cell proliferation was detected using the Proliferation ELISA kit (Roche Diagnostics GmbH, Penzberg, Germany). The two cell lines were plated at a density of $5 \times 10^{3}$ cells/well in 96 -well plates with $100 \mu \mathrm{l} /$ well growth medium and incubated for $24 \mathrm{~h}$ at $37^{\circ} \mathrm{C}$. Cells were starved for $24 \mathrm{~h}$ in RPMI-1640 medium without FCS supplementation, and then treated for 24 or $48 \mathrm{~h}$ with $6.25-1,600 \mathrm{ng} / \mathrm{ml}$ leptin in replicates of six in starvation medium. During treatment, the medium was supplemented with $10 \mu \mathrm{M}$ BrdU. Cell proliferation was assessed as previously described (16). The experiment was repeated for a total of three independent times. Each experiment had six replicates for each leptin concentration.

PI3K and MAPK phosphorylation ELISA. Cell-based ELISA Phospho-Akt (S473) Immunoassay and Phospho-extracellular signal-regulated kinase (ERK)1/ERK2 (T202/Y204) Immunoassay were purchased from R\&D Systems (Abingdon, UK). The cells were plated in a supplied clear bottom, black-walled, 96-well plate at a density of $5 \times 10^{3}$ cells/well with $100 \mu \mathrm{l} /$ well growth medium, and incubated for $24 \mathrm{~h}$ at $37^{\circ} \mathrm{C}$. The cells were starved for $24 \mathrm{~h}$ as mentioned above and then treated with $1,600 \mathrm{ng} / \mathrm{ml}$ leptin for 5-20 min in duplicates. Phosphorylation of protein kinase B (Akt) or ERK1/2 was then assessed as previously described (16). The experiment was repeated for a total of three independent experiments with two replicates for each time point in each experiment.
Cell cycle analysis. Changes in the cell distribution across cell cycle stages were assessed by measuring the DNA content in cells using flow cytometry following leptin treatment. The DNA-specific dye was propidium iodide (PI; Sigma-Aldrich, Gillingham, UK). The cells were plated at a density of $5 \times 10^{5}$ cells/well in six-well plates with $3 \mathrm{ml}$ growth medium, and incubated for $24 \mathrm{~h}$ at $37^{\circ} \mathrm{C}$. The cells were starved for $24 \mathrm{~h}$, treated with $1,600 \mathrm{ng} / \mathrm{ml}$ leptin for $24 \mathrm{~h}$ and then harvested, treated and analyzed as described previously (16).

Statistical analysis. The findings were analyzed for statistical significance using univariate analysis of variance between the control and each treatment concentration for cell proliferation analysis and between the control and each time point in the cell signaling pathway analysis, followed by Dunnett's post hoc t-tests. Differences in the distribution across cell cycle stages between the control and leptin-treated cells were assessed for each cell cycle stage using Student's t-test. $\mathrm{P}<0.05$ was considered to indicate a statistically significant difference.

\section{Results}

Changes in cell proliferation following leptin treatment. In the SK-BR-3 cells, proliferation increased by 61, 96, 104, 115, 115,110 and $51 \%$ following treatment with $6.25,12.5,25,50$, 100, 200 and $400 \mathrm{ng} / \mathrm{ml}$ leptin, respectively, for $24 \mathrm{~h}$ compared with the untreated control (all $\mathrm{P}<0.001$ ) (Fig. 1A). There was no significant difference in cell proliferation between the untreated cells and cells treated with 800 or 1,600 ng/ml leptin for $24 \mathrm{~h}$ (Fig. 1A). After $48 \mathrm{~h}$ of treatment, cell proliferation increased significantly by $44,53,53,69,75,69,52$ and $33 \%$ following treatment with $6.25,12.5,25,50,100,200,400 \mathrm{ng} / \mathrm{ml}$ (all $\mathrm{P}<0.001)$ and $800 \mathrm{ng} / \mathrm{ml}(\mathrm{P}=0.009)$ leptin, respectively compared with the untreated control (Fig. 1B). There was no change in proliferation after $48 \mathrm{~h}$ of treatment with 1,600 ng/ml leptin (Fig. 1B). In MDA-MB-231 breast cancer cells, proliferation did not change significantly after $24 \mathrm{~h}$ of treatment with leptin (Fig. 1C) and decreased significantly by $11 \%(\mathrm{P}=0.023)$ and $26 \%(\mathrm{P}<0.001)$ after $48 \mathrm{~h}$ of treatment with 400 and $800 \mathrm{ng} / \mathrm{ml}(\mathrm{P}<0.001)$ of leptin, respectively, compared with the untreated control (Fig. 1D). Based on the findings obtained on growth inhibition following treatment with $1,600 \mathrm{ng} / \mathrm{ml}$ leptin, cell signaling and cell cycle changes were assessed to determine the underlying mechanisms responsible for growth inhibition in the two breast cancer cell lines.

Changes in PI3K and MAPK cell signaling pathway activity following leptin treatment. In the SK-BR-3 cells, Akt-phosphorylation did not change significantly following treatment with $1,600 \mathrm{ng} / \mathrm{ml}$ leptin for up to $20 \mathrm{~min}$ compared with the control (Fig. 2A). ERK1/2-phosphorylation decreased by 32 and $34 \%$ after $10(\mathrm{P}<0.001)$ and $15 \mathrm{~min}(\mathrm{P}<0.001)$ of treatment with $1,600 \mathrm{ng} / \mathrm{ml}$ leptin, respectively, compared with the control (Fig. 2B). In the MDA-MB-231 cells, Akt-phosphorylation did not change significantly following treatment with 1,600 ng/ml leptin (Fig. 2C), whereas ERK1/2-phosphorylation decreased significantly by 17 and $20 \%$ after $15(\mathrm{P}=0.026)$ and $20 \mathrm{~min}(\mathrm{P}=0.011)$ of treatment with $1,600 \mathrm{ng} / \mathrm{ml}$ leptin, respectively, compared with the control (Fig. 2D). 
Table I. Changes of cell population distribution across cell cycle stages after $24 \mathrm{~h}$ of treatment with 1,600 ng/ml leptin.

\begin{tabular}{|c|c|c|c|c|c|c|}
\hline \multirow[b]{2}{*}{ Cell cycle stage $(\%)$} & \multicolumn{2}{|c|}{ SK-BR-3 cells } & \multirow[b]{2}{*}{ P-value } & \multicolumn{2}{|c|}{ MDA-MB-231 cells } & \multirow[b]{2}{*}{ P-value } \\
\hline & Control & Leptin-treated & & Control & Leptin-treated & \\
\hline $\mathrm{SubG}_{1}$ & $20.56 \pm 3.01$ & $20.4 \pm 1.68$ & 0.2189 & $17.00 \pm 1.07$ & $18.15 \pm 1.33$ & 0.5077 \\
\hline $\mathrm{G}_{0} / \mathrm{G}_{1}$ & $39.90 \pm 2.00$ & $44.385 \pm 2.10$ & 0.1490 & $55.12 \pm 0.97$ & $54.14 \pm 0.99$ & 0.3830 \\
\hline S & $6.30 \pm 0.45$ & $5.86 \pm 0.81$ & 0.6444 & $7.23 \pm 0.65$ & $6.96 \pm 0.62$ & 0.7677 \\
\hline $\mathrm{G}_{2}$ & $15.98 \pm 0.70$ & $14.03 \pm 0.87$ & 0.0863 & $12.88 \pm 0.43$ & $12.71 \pm 0.48$ & 0.4257 \\
\hline
\end{tabular}

Values represent the mean \pm standard error of three independent experiments. P-values were determined by Student's t-test. Each experiment had two replicates, i.e., six data points for control and treatment.

A

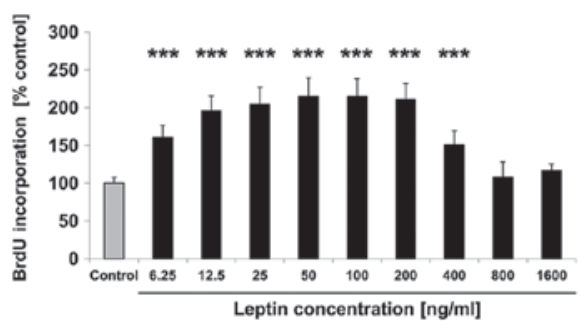

C

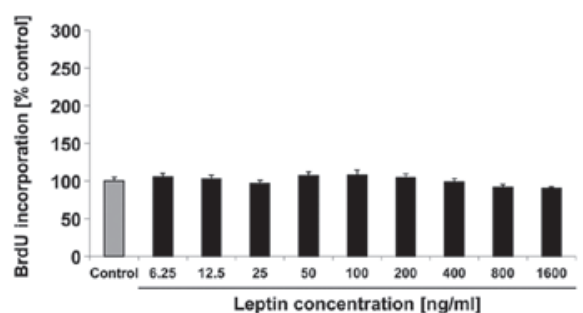

B

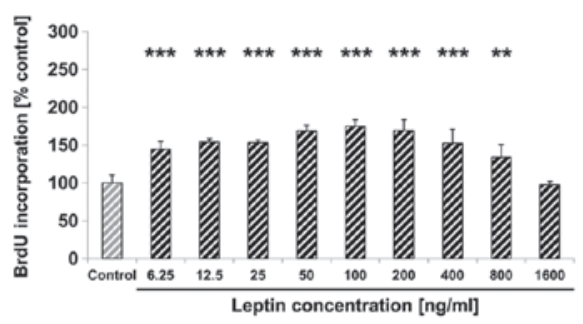

D

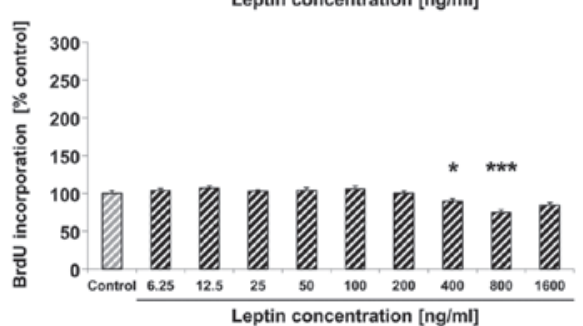

Figure 1. Changes in cell proliferation following treatment of (A and B) SK-BR-3 and (C and D) MDA-MB-231 breast cancer cells for (A and C) $24 \mathrm{~h}$ and (B and D) $48 \mathrm{~h}$, with a range of leptin concentrations. Bars represent BrdU incorporation in relation to the respective control within each graph, and are expressed as a percentage of the control. Error bars represent standard error of the mean of two experiments, each consisting of six replicates, i.e., 12 data points for each bar. Significance was determined using Dunnett's post hoc t-test following one-way analysis of variance ( $\mathrm{P}<0.05,{ }^{* * *} 0.01<\mathrm{P}<0.001$ and ${ }^{* * * *} \mathrm{P}<0.001$, vs. the control). BrdU, bromodeoxyuridine

A

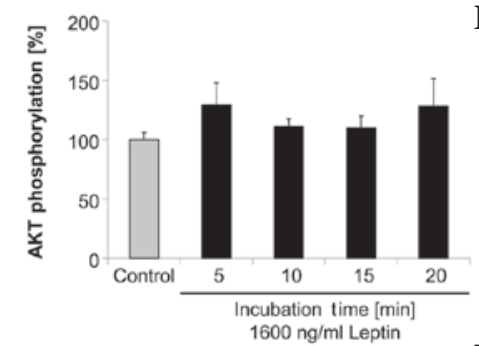

C

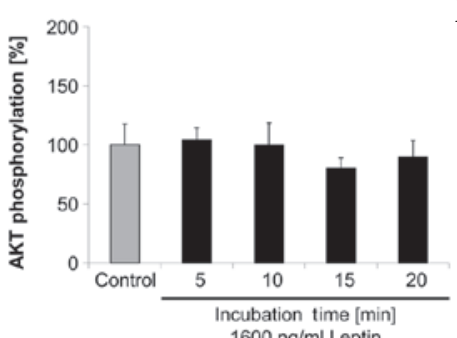

B

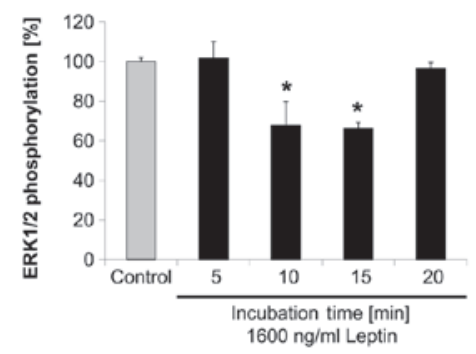

D

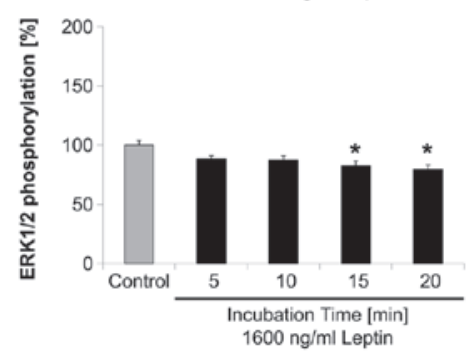

Figure 2. Changes in (A and C) Akt phosphorylation and (B and D) ERK1/2 phosphorylation as indicators of changes in the PI3K or MAPK cell signaling pathway, respectively, following 1,600 ng/ml leptin treatment of (A and B) SK-BR-3 and (C and D) MDA-MB-231 breast cancer cells for the indicated time periods. Bars represent Akt or ERK1/2-phosphorylation in relation to their respective control within each graph, and are expressed as a percentage of the control. Error bars represent standard error of the mean of three experiments, each consisting of two replicates, i.e., six data points for each bar. Significance was obtained using Dunnett's post hoc t-test following univariate analysis of variance ("P $<0.05$, vs. the control). ERK, extracellular signal-regulated kinase; PI3K, phosphatidylinositide-3 kinase; MAPK, mitogen-activated protein kinase. 
Changes in distribution of cell population across cell cycle stages. In the SK-BR-3 cells, 1,600 ng/ml leptin treatment may increase the $\mathrm{G}_{1}$-phase population and decrease the $\mathrm{G}_{2}$-phase population (Table I). Cells in the $\mathrm{G}_{1}$-phase increased by 4.5 percentage points (11\% increase) and cells in the $\mathrm{G}_{2}$-phase decreased by 2.0 percentage points ( $12 \%$ decrease). In MDA-MB-231 cells, the subG $\mathrm{G}_{1}$-phase population increased by 1.2 percentage points ( $7 \%$ increase) and the $\mathrm{G}_{1}$-phase population decreased by 1.0 percentage point ( $2 \%$ decrease) following treatment with $1,600 \mathrm{ng} / \mathrm{ml}$ leptin (Table I). None of the observed changes were significantly different.

\section{Discussion}

Previous in vitro studies have demonstrated that leptin induces cell proliferation in a variety of breast cancer cell types, within physiological concentrations $(25-100 \mathrm{ng} / \mathrm{ml})(6,9-12,18)$. Conversely, the same studies did not observe increased cell proliferation with leptin concentrations exceeding $100 \mathrm{ng} / \mathrm{ml}$. The findings of the present study confirmed the increased cell proliferation in SK-BR-3 breast cancer cells, but not in MDA-MB-231 cells at physiological concentrations. Furthermore, leptin treatment at supraphysiological concentrations did not increase cell proliferation in the SK-BR-3 cells, but inhibited proliferation of the MDA-MB-231 cells. To the best of our knowledge, this study was the first to indicate the potential of leptin treatment to inhibit cell proliferation in breast cancer cells. The mechanism by which supraphysiological leptin concentrations induce growth inhibition may involve decreased activation of the Ras-mediated MAPK pathway.

As a potential explanation, leptin may interact with the HER-2/neu receptor in SK-BR-3 breast cancer cells, which is overexpressed in these cells, resulting in decreased MAPK activity. Soma et al reported that SK-BR-3 cells treated with leptin $(500 \mathrm{ng} / \mathrm{ml})$ resulted in increased phosphorylation of the HER-2/neu receptor (20). This cross-talk was identified as being responsible for an increase in ERK1/2 phosphorylation, which was also observed following leptin treatment. The findings of the present study suggest that at higher leptin concentrations, this effect is inhibited. This may either be by high leptin levels inhibiting the potential of HER-2/neu to activate ERK1/2 or by inhibiting ERK1/2 phosphorylation directly. HER-2/neu and $\mathrm{Ob}-\mathrm{R}$ transduct their proliferative signal through the PI3K and/or MAPK pathways (21), suggesting there may be an interaction on the targets downstream of the two receptors. Thus, leptin may have at least two modes of action, which appear to be antagonistic. First, leptin increases phosphorylation of HER-2/neu, which results in increased proliferation of SK-BR-3 breast cancer cells; second, leptin inhibits ERK1/2 phosphorylation, which is predominant at high leptin concentrations, thereby reducing the effect of increased HER-2/neu signaling.

In MDA-MB-231 breast cancer cells, which are HER-2-negative, interplay with HER-2/neu cannot account for the observed reduction in proliferation, indicating that growth inhibition at supraphysiological leptin concentrations is HER-2/neu independent. In a study aiming to potentiate the antitumor effects of cAMP-agonists, leptin induced apoptosis in MDA-MB-231 breast cancer cells when cAMP levels were increased (22), which resulted in ERK1/2 inactivation and the subsequent inhibition of protein kinase A (PKA) expression (23). Thus, at supraphysiological concentrations, leptin may not require elevated cAMP levels to decrease PKA, and this may provide a mechanism for the effects observed in our study.

These findings suggest that leptin exerts a biphasic effect on cell proliferation in SK-BR-3 breast cancer cells and that leptin signaling may play a role in breast cancer development and progression. Therefore, the inhibition of leptin signaling may be relevant for breast cancer prevention, particularly for obese individuals showing high levels of leptin and occurrence of breast cancer. Nutritional interventions (24) or anti-leptin treatment (25) may be considered as a potential preventative strategy and treatment for HER-2/neu overexpressing breast tumors, respectively. Further investigations into the inhibitory effects of leptin at high concentrations may reveal the unknown mechanisms in the connection between obesity and postmenopausal breast cancer.

\section{References}

1. Calle EE, Rodriguez C, Walker-Thurmond K and Thun MJ: Overweight, obesity, and mortality from cancer in a prospectively studied cohort of U.S. adults. N Engl J Med 348: 1625-1638, 2003.

2. Lorincz AM and Sukumar S: Molecular links between obesity and breast cancer. Endocr Relat Cancer 13: 279-292, 2006.

3. Considine RV, Sinha MK, Heiman ML, et al: Serum immunoreactive-leptin concentrations in normal-weight and obese humans. N Engl J Med 334: 292-295, 1996.

4. Zhang Y, Proenca R, Maffei M, et al: Positional cloning of the mouse obese gene and its human homologue. Nature 372: 425-432, 1994.

5. Stephens TW, Basinski M, Bristow PK, et al: The role of neuropeptide $\mathrm{Y}$ in the antiobesity action of the obese gene product. Nature 377: 530-532, 1995.

6. Hu X, Juneja SC, Maihle NJ and Cleary MP: Leptin - a growth factor in normal and malignant breast cells and for normal mammary gland development. J Natl Cancer Inst 94: 1704-1711, 2002.

7. Tessitore L, Vizio B, Pesola D, et al: Adipocyte expression and circulating levels of leptin increase in both gynaecological and breast cancer patients. Int J Oncol 24: 1529-1535, 2004.

8. Révillion F, Charlier M, Lhotellier V, et al: Messenger RNA expression of leptin and leptin receptors and their prognostic value in 322 human primary breast cancers. Clin Cancer Res 12: 2088-2094, 2006.

9. Ishikawa M, Kitayama J and Nagawa $H$ : Enhanced expression of leptin and leptin receptor (OB-R) in human breast cancer. Clin Cancer Res 10: 4325-4331, 2004.

10. Frankenberry KA, Skinner H, Somasundar P, McFadden DW and Vona-Davis LC: Leptin receptor expression and cell signaling in breast cancer. Int J Oncol 28: 985-993, 2006.

11. Ray A, Nkhata KJ and Cleary MP: Effects of leptin on human breast cancer cell lines in relationship to estrogen receptor and HER2 status. Int J Oncol 30: 1499-1509, 2007.

12. Dieudonne MN, Machinal-Quelin F, Serazin-Leroy V, Leneveu MC, Pecquery R and Giudicelli Y: Leptin mediates a proliferative response in human MCF7 breast cancer cells. Biochem Biophys Res Commun 293: 622-628, 2002.

13. Costantino A, Milazzo G, Giorgino F, et al: Insulin-resistant MDA-MB231 human breast cancer cells contain a tyrosine kinase inhibiting activity. Mol Endocrinol 7: 1667-1676, 1993.

14. Weichhaus M, Broom J, Wahle K and Bermano G: A novel role for insulin resistance in the connection between obesity and postmenopausal breast cancer. Int J Oncol 41: 745-752, 2012.

15. Rivas MA, Carnevale RP, Proietti CJ, et al: TNF alpha acting on TNFR1 promotes breast cancer growth via p42/P44 MAPK, JNK, Akt and NF-kappa B-dependent pathways. Exp Cell Res 314: 509-529, 2008.

16. Weichhaus M, Broom I and Bermano G: The molecular contribution of TNF-alpha in the link between obesity and breast cancer. Oncol Rep 25: 477-483, 2011. 
17. Chen C, Chang YC, Liu CL, Chang KJ and Guo IC: Leptin-induced growth of human ZR-75-1 breast cancer cells is associated with up-regulation of cyclin D1 and c-Myc and down-regulation of tumor suppressor p53 and p21WAF1/CIP1. Breast Cancer Res Treat 98: 121-132, 2006.

18. Laud K, Gourdou I, Pessemesse L, Peyrat JP and Djiane J: Identification of leptin receptors in human breast cancer: functional activity in the T47-D breast cancer cell line. Mol Cell Endocrinol 188: 219-226, 2002.

19. Okumura M, Yamamoto M, Sakuma H, et al: Leptin and high glucose stimulate cell proliferation in MCF-7 human breast cancer cells: reciprocal involvement of PKC-alpha and PPAR expression. Biochim Biophys Acta 1592: 107-116, 2002.

20. Soma D, Kitayama J, Yamashita H, et al: Leptin augments proliferation of breast cancer cells via transactivation of HER2. J Surg Res 149: 9-14, 2008.

21. Reese DM and Slamon DJ: HER-2/neu signal transduction in human breast and ovarian cancer. Stem Cells 15: 1-8, 1997.
22. Naviglio S, Di Gesto D, Romano M, et al: Leptin enhances growth inhibition by cAMP elevating agents through apoptosis of MDA-MB-231 breast cancer cells. Cancer Biol Ther 8: 1183-1190, 2009

23. Naviglio S, Di Gesto D, Illiano F, et al: Leptin potentiates antiproliferative action of cAMP elevation via protein kinase A down-regulation in breast cancer cells. J Cell Physiol 225: 801-809, 2010

24. Fan C, Liu X, Shen W, Deckelbaum RJ and Qi K: The regulation of leptin, leptin receptor and pro-opiomelanocortin expression by N-3 PUFAs in diet-induced obese mice is not related to the methylation of their promoters. Nutr Metab (Lond) 8: 31, 2011.

25. Guo S, Liu M, Wang G, et al: Oncogenic role and therapeutic target of leptin signaling in breast cancer and cancer stem cells. Biochim Biophys Acta 1825: 207-222, 2012. 